\title{
Factors correlated to non-adherence to antiretroviral therapy among immigrants from poor resource countries, attending a reference center in Rome
}

\author{
P Pierro, P Lorenzini, MP Trotta*, P Sette, ML Giancola, N Orchi, \\ M Giulianelli, P De Longis, U Visco-Comandini, A Antinori and M Zaccarelli
}

Address: INMI "L. Spallanzani", Rome, Italy

* Corresponding author

from Ninth International Congress on Drug Therapy in HIV Infection

Glasgow, UK. 9-13 November 2008

Published: 10 November 2008

Journal of the International AIDS Society 2008, I I (SuppI I):PI69 doi:10.II86/I758-2652-II-SI-PI69

This abstract is available from: http://www.jiasociety.org/content/II/SI/PI69

(c) 2008 Pierro et al; licensee BioMed Central Ltd.

\section{Background}

The management of antiretroviral treatment patients from poor resources countries, whose number is progressively increasing in western Europe, requires understanding of different behaviors and attitudes towards HIV infection.

\section{Methods}

Patients attending the center are involved in a routine program including a brief self-reported adherence questionnaire, together with collection of behavioral data. Counseling for HIV infection and adherence intervention are routinely provided. Physicians, psychologist and social workers are involved. A preliminary analysis of data collected from the first years of activity is reported.

\section{Summary of results}

Up to now, 89 patients completed the questionnaire: $44.9 \% \mathrm{M}, 33.7 \% \mathrm{~F}, 21.4 \%$ trans-sexuals; median age 41 years (IQR 34-48); 36.0\% Latin America, 28.1\% subSaharan Africa, $18.0 \%$ East Europe, 9.0\% North Africa/ Middle East, $8.9 \%$ other origins; $10.2 \%$ use of cocaine, $2.3 \%$ intravenous drug-use. Moreover, $34.0 \%$ reported no sex contact in the past 6 months, and $23.9 \%$ reported prostitution. Regular condom use was reported by only $9.0 \%$.

Full adherence $(100.0 \%)$ in the past month was reported by $60.7 \%$ of patients. Moreover, $23.6 \%$ of patients reported treatment interruption, $14.6 \%$ refill problems in the past 3 months, and $19.1 \%$ of patients reported missed doses in the past week. Lack of achieving adherence in any of the questions was considered non-adherence and set as dependent variable in a logistic regression model.

At adjusted logistic regression a significantly better adherence was found among males (OR: 0.21 ; 95\% CI: $0.05-$ 0.85, $\mathrm{p}=0.029$ ) and trans-sexuals (OR: 0.03, 95\% CI: $0.001-0.63, \mathrm{p}=0.025)$ compared to females, while higher non-adherence was observed among patients who did not report regular condom use (OR: 5.52, 95\% CI: 1.5120.20, $\mathrm{p}=0.01$ ) and marginally among individuals from Latin America (OR: 6.34, 95\% CI: 0.85-47.57, p = 0.07). Women appeared to be less informed about HIV transmission and treatment.

\section{Conclusion}

In this specific setting of immigrant population, worst sexual behavior and less knowledge are associated with nonadherence. Conversely, non-adherence failed to be associated with substance abuse. Thus our program is ongoing and enhancing. We plan to evaluate changes in behavior and adherence after repeated counseling, to target intervention to specific subgroups, also using cultural opinionleaders, following information collected. 